\title{
The effect of suppressive thyroxine therapy in nodular goiter in postmenopausal women and 2 year's bone mineral density change
}

\author{
Chiung-Ya Chen, Szu-Tah Chen, Bie-Yu Huang, Jawl-Shan Hwang, Jen-Der Lin and Feng-Hsuan Liu
}

Division of Endocrinology and Metabolism, Department of Internal Medicine, Chang Gung Memorial Hospital, Chang Gung University, Kweishan, Taoyuan, Taiwan

\begin{abstract}
The efficacy of thyroxine suppressive therapy in reducing nodular growth and its effect to bone mineral density (BMD) in postmenopausal women is still debated. This study aimed to evaluate the therapeutic effect of thyroxine and its influence on BMD. Postmenopausal women with nodular or multinodular goiter during 2013-2015 at Chang Gung Memorial Hospital were enrolled and retrospectively traced back to the first date of visit or treatment. Ninety-four eligible patients were enrolled, of whom 45 were thyroxine-treated (LT-4 group) and 49 were treatment-naïve (control group). Data, including volume of nodules, were analyzed retrospectively. BMD was measured in each LT-4 group patient since the year of enrollment. Nodular volumes were reduced in both LT-4 (from $4.89 \pm 4.46$ to $4.10 \pm 4.57 \mathrm{~mL}, p=0.033$ ) and control group $(3.48 \pm 4.36$ to $3.09 \pm 2.88 \mathrm{~mL}, p=0.239)$ at initial 2-year follow-up. Nodular volume in LT-4 group increased insignificantly (from $4.89 \pm 4.46$ to $4.91 \pm 5.40 \mathrm{~mL}, p=0.711$ ) at the end of 7-year follow-up. The best cut-off predictive nodular volume that may have responded to thyroxine is $2.6 \mathrm{~mL}$ (AUC, 0.740; sensitivity, 0.750; specificity, 0.733) during first 2 year. Lumbar spine, total hip and femoral neck BMD were not significantly changed during 2 year's thyroxine suppression therapy. In conclusion, thyroxine suppressive therapy in postmenopausal women had significant reduction in nodule volume at initial 2 years of treatment, especially in volume larger than $2.6 \mathrm{~mL}$. Prolonged thyroxine treatment did not benefit nodular size reduction and may affect BMD minimally in postmenopausal women.
\end{abstract}

Key words: Thyroxine, Multinodular goiter, Bone mineral density

THYROID NODULAR GOITER has an increasing trend worldwide with prevalence ranging from $19 \%$ to $68 \%$ and higher frequency in older adults, especially in women [1]. The prevalence of goiter has been estimated to be $25 \%$ in Taiwan, with $19.4 \%$ in males and $33.6 \%$ in females.

The therapeutic effect of thyroxine on thyroid nodular goiter has been well studied, but with mixed results in the effectiveness of reducing the volume of thyroid nodules. Responsiveness to suppression of thyroid stimulating hormone (TSH) as a way to reduce nodular size was satisfactory in several studies [2-4], but not in all studies

Submitted Mar. 28, 2018; Accepted Jul. 13, 2018 as EJ18-0125 Released online in J-STAGE as advance publication Aug. 30, 2018 Correspondence to: Feng-Hsuan Liu, MD, Division of Endocrinology and Metabolism, Department of Internal Medicine, Chang Gung Memorial Hospital, Chang Gung University, Kweishan, No. 5, Fuxing St., Guishan Dist., Taoyuan City 333, Taiwan (R.O.C.). E-mail: a122liu@cgmh.org.tw
[5-8]. The conflicting data on outcomes may be due to differences in gender, age, duration of therapy, suppressed or non-suppressed TSH levels, initial nodule size, nodule characteristics, the definition of responder or non-responder, and whether the patient was menopausal or not [9].

Aside from the therapeutic effect of thyroxine, possible adverse effects of thyroxine are worrisome, including increased risk of atrial fibrillation (Af) and cardiovascular disease in older adults with low TSH levels [10-14]. The action of thyroid hormone on the human skeleton has also been reviewed $[15,16]$, and low TSH level was proposed as a direct negative regulator of bone turnover [16]. For example, Surks et al. [17] reported an association between bone mineral density (BMD) loss and subclinical hyperthyroidism. Although some studies found that thyroxine treatment had a minimal effect on bone loss $[18,19]$, it is worth noting that women are known to have decreased BMD on aging, which accelerates after 
menopause. Aging is also noted for increased risk of osteoporosis-related fracture and associated co-morbidity and mortality [20].

The objective of this study was to evaluate the therapeutic effect of thyroxine in postmenopausal women with thyroid nodule goiter and the possible effect of thyroxine on changes in BMD. Results may provide useful clinical information for the clinician managing thyroid nodules, especially in postmenopausal women.

\section{Material and Methods}

\section{Patients and study design}

Postmenopausal women with nodular or multinodular goiter seen during the period from 2013 to 2015 at the outpatient department of Chang Gung Memorial Hospital (CGMH), Taipei, Taiwan were included in the study. The records of enrolled women were retrospectively reviewed back to the date of the first visit for the condition. Taipei is a metropolitan and non-endemic area for goiter in Taiwan. Postmenopausal women were identified and enrolled who either received thyroxine (Aspen Pharmacare, Germany and GlaxoSmithKline Pharmaceuticals, United Kingdom) treatment (LT-4 group) or not (Control group) during the study period.

In LT-4 group, thyroxine was started before the time of enrollment and was traced back to the year 2001 in the earliest record. In control group, the size of nodules was traced back to the year 2002 in the earliest record and the observation period was 5 years. In all subjects in both groups, the goiters were identified before enrollment in the study, and the baseline of the control and LT-4 group was the time point when the nodules were found. The dose of thyroxine was adjusted and maintained at the minimal dose to keep the thyroid hormone (T4) level within the normal range, and TSH below the lowest normal limit reference range $(<0.35 \mu \mathrm{IU} / \mathrm{mL})$, but above the lowest detectable limit $(>0.008 \mu \mathrm{IU} / \mathrm{mL})$ to avoid thyrotoxicosis. Postmenopausal status was defined by the cutoff point of age 50 [21,22], or according to the patients' medical chart record.

The study protocol was reviewed and approved by the Ethics Committee on Research and The Institutional Review Board of CGMH.

\section{Selection criteria}

The following inclusion criteria were used: (a) single or multiple thyroid nodules diagnosed by ultrasonography (US); (b) diagnosis of benign lesion from fine needle aspiration cytology (FNAC) according to the Bethesda's criteria [23]; (c) US characteristics of a solid nodule with less than $50 \%$ of cystic components; (d) normal thyroid function without previous thyroid hormone and/or antithyroid drug treatment. The exclusion criteria were: (a) US characteristics of cystic component $>90 \%$ [24]; (b) confirmed or suspected of malignancy and/or neoplasm; (c) history or current hyperthyroidism and/or hypothyroidism under treatment, and (d) history of neck irradiation. Patients who treated or ever treated with the human monoclonal antibody to the receptor activator of nuclear factor-kappa B ligand (RANKL), selective estrogenreceptor modulator (SERM), and bisphosphate for osteoporosis were also excluded. Accordingly, while 77 patients were initially included in LT-4 group, 17 preand perimenopause subjects, 4 with previous hypothyroidism, 2 with previous hyperthyroidism, 2 with pure cystic component, 2 with suspicion of follicular neoplasm, and 5 with non-suppressible TSH level were excluded, leaving a total of 45 patients in LT-4 group. Similarly, 2 out of 51 patients in control group were excluded due to premenopausal status (Fig. 1). All of the nodules were carefully examined to fit the inclusion criteria, and all of the nodules were measured carefully after the assurance the same lesion during follow-up. Meanwhile, 32 patients who received at least 2 consecutive BMD tests during thyroxine suppression therapy in LT-4 group were analyzed for change of BMD. The baseline BMD in the study was the first time when participants were enrolled and the time point may allocate at several years after LT-4 administration.

\section{Measurements}

Ultrasound examination was performed with a commercially available real-time instrument (Hitachi Avius and Aloka alpha 5 with a high resolution $7.5 \mathrm{MHz}$ linear probe; Hitachi, Japan) capable of visualizing solid lesions down to $3 \mathrm{~mm}$ size and with a theoretical axial resolution of less than $1 \mathrm{~mm}$. In both L-T4 and control groups, US examinations were performed at 6-12 months intervals after the first visit. The timeframe of US follow-up was determined by a routine schedule or pro re nata according to physician's judgment.

US characteristics of the nodules were divided into solid, or mixed type (pure cystic lesions were excluded). As a rule, measurements of the nodules were taken as longitudinal (D1), transverse (D2) and depth (D3). The nodule volume was calculated according to the ellipsoid formula: 


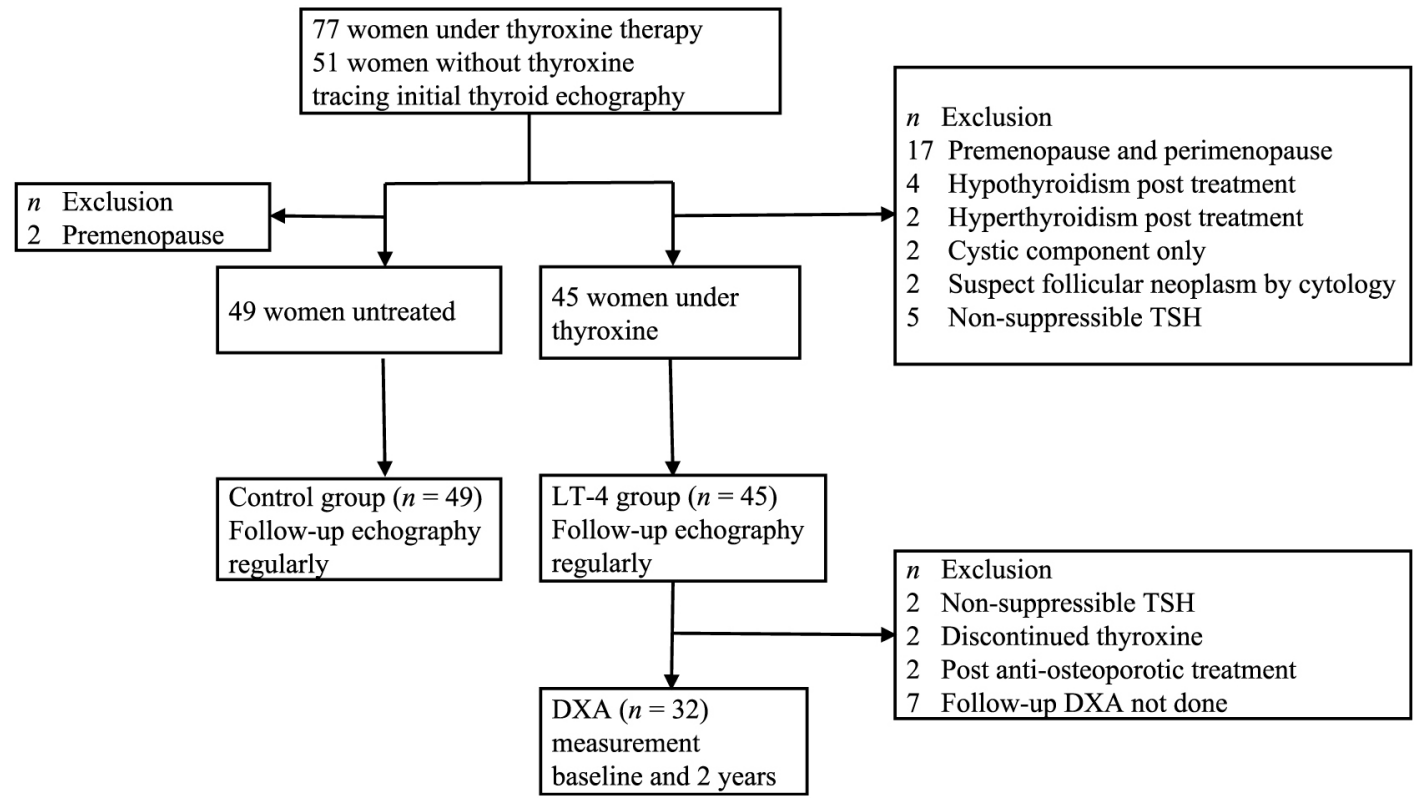

Fig. 1 Flowchart of participants

Volume $(\mathrm{mL})=\mathrm{D} 1(\mathrm{~cm}) \times \mathrm{D} 2(\mathrm{~cm}) \times \mathrm{D} 3(\mathrm{~cm}) \times \pi / 6$ [25]

FNAC was done by a 23 or 25 -gauge needle, as previously reported [23].

\section{Bone mineral density}

BMD was measured using a dual-energy X-ray absorption (DXA) fan-beam bone densitometer (Lunar Prodigy; GE Health-care Bio-Sciences, Piscataway, NJ, USA) at the lumbar 1-4 levels of the posterior-anterior spine, femoral neck, and total hip. Coefficient of variation was less than $1 \%$ in all centers where the densitometries were performed. The T-score, calculated using bone density data from the reference range of a healthy Caucasian female population [26].

\section{Laboratory tests}

Serum thyroglobulin ( $\mathrm{Tg}$ ) was detected by chemiluminescence immunoassay (CLIA) using immunoassay systems (Beckman Coulter, Inc. Brea, CA 92821, USA). Anti-thyroid peroxidase antibody (anti-TPO Ab) was checked by chemiluminescence microparticle immunoassay (CMIA) with the Architect i2000 system (Abbott Laboratories Diagnostics Division, IL, USA). T4 and TSH were examined using CLIA methodology on the Advia Centaur XPi system (Siemens, Germany). Roche e602 modular immunoassay analyzer (Elecsys, Roche Diagnostics, Mannheim, Germany) was used to detect
anti-Tg and anti-TSH receptor Abs. The reference range for T4, TSH and Tg were 4.8-12.5 $\mu \mathrm{g} / \mathrm{dL}, 0.35-5.50$ $\mu \mathrm{IU} / \mathrm{mL}$ and $<25 \mathrm{ng} / \mathrm{mL}$, respectively. The normal range for anti-Tg Ab, anti-TPO $\mathrm{Ab}$ and anti-TSH receptor $\mathrm{Ab}$ were $<115 \mathrm{IU} / \mathrm{mL},<5.6 \mathrm{IU} / \mathrm{mL}$, and $<1.75 \mathrm{IU} / \mathrm{L}$, respectively. The hormone measurements and clinical evaluations were repeated in the follow-up period.

\section{Statistical analysis}

All statistical analyses were performed using the Statistical Product and Service Solutions (SPSS, version 20, IBM Corp., New York, USA). Differences in age, body weight, body mass index (BMI), TSH, T4, and Tg were compared between groups by Mann-Whitney $U$ test, and autoimmune antibodies such as anti-Tg Ab and anti-TPO Ab, anti-TSH Ab were compared between groups by Fisher's exact test. Comparisons between baseline and annual nodule volumes were performed by Wilcoxon signed-rank test. Receiver operating characteristic (ROC) curve was performed to determine the cut-off point for best specificity and sensitivity. The best discrimination point of initial thyroid nodule volume was determined by Youden index [27]. Paired student $t$-test was used to evaluate changes in BMD after serial DXA measurement. A $p$ value of less than 0.05 was established as statistical significance. 
Table 1 Demographic, clinical and biochemical data of postmenopausal patients

\begin{tabular}{|c|c|c|c|c|c|}
\hline & Baseline Control & LT-4 & $p$ value & $\begin{array}{l}\text { After suppressive } \\
\text { thyroxine LT- } 4\end{array}$ & $p$ value \\
\hline$n$ & 49 & 45 & & 45 & \\
\hline Age at study entry (years) & $63.3 \pm 7.3$ & $60.6 \pm 8.4$ & 0.123 & & \\
\hline Height $(\mathrm{cm})$ & $155.2 \pm 6.3$ & $157.7 \pm 5.0$ & $0.041^{*}$ & & \\
\hline Weight (kg) & $59.0 \pm 10.1$ & $57.8 \pm 7.2$ & 0.843 & & \\
\hline Body mass index $\left(\mathrm{kg} / \mathrm{m}^{2}\right)$ & $24.2 \pm 4.4$ & $23.2 \pm 2.8$ & 0.765 & & \\
\hline Anti-TPO (positive), $n(\%)$ & $5(10.2 \%)$ & $6(13.3 \%)$ & 0.753 & & \\
\hline Anti-TSHR (positive), $n(\%)$ & $0(0 \%)$ & $1(2.2 \%)$ & 0.479 & & \\
\hline Anti-Tg (positive), $n(\%)$ & $2(4.1 \%)$ & $4(8.9 \%)$ & 0.421 & & \\
\hline $\mathrm{TSH}(\mu \mathrm{IU} / \mathrm{mL})$ & $1.31 \pm 0.67$ & $1.11 \pm 0.48$ & 0.565 & $0.13 \pm 0.15$ & $<0.001^{*}$ \\
\hline $\operatorname{Tg}(\mathrm{ng} / \mathrm{mL})$ & $14.6 \pm 10.3$ & $79.5 \pm 122.4$ & $0.001 *$ & $32.0 \pm 51.9$ & $0.006^{*}$ \\
\hline $\mathrm{T} 4(\mu \mathrm{g} / \mathrm{dL})$ & $8.3 \pm 1.6$ & $10.6 \pm 9.1$ & 0.827 & $10.9 \pm 2.2$ & $0.023 *$ \\
\hline Nodule volume $(\mathrm{mL})$ & $3.48 \pm 4.36$ & $4.89 \pm 4.46$ & 0.066 & & \\
\hline Thyroxine dose ( $\mu \mathrm{g} /$ day $)$ & & & & $104.9 \pm 19.0$ & \\
\hline Thyroxine dose ( $\mu \mathrm{g} / \mathrm{kg} /$ day) & & & & $1.8 \pm 0.4$ & \\
\hline Duration of thyroxine therapy (months) & & & & $91.2 \pm 44.7$ & \\
\hline
\end{tabular}

Continuous variables are presented as mean and standard deviation (mean $\pm \mathrm{SD}$ ). Nonparametric Mann-Whitney $U$ test was used for continuous variables. Fisher's exact test was used for nominal variables.

* Significant difference, defined by $p$ value $<0.05$.

Abbreviations: anti-TPO Ab, anti-thyroid peroxidase antibody; anti-TSHR, anti-thyroid stimulating hormone receptor antibody; anti-Tg $\mathrm{Ab}$, anti-thyroglobulin antibody; T4, Thyroid hormone thyroxine.

\section{Results}

All participants were euthyroid and postmenopausal when enrolled. The mean age was $63.3 \pm 7.3$ years in control group and $60.6 \pm 8.4$ years in LT-4 group ( $p=$ 0.123 , Table 1). BMI was similar between the two groups $\left(24.2 \pm 4.4 \mathrm{~kg} / \mathrm{m}^{2}\right.$ in control group and $23.2 \pm 2.8$ $\mathrm{kg} / \mathrm{m}^{2}$ in LT-4 group, $p=0.843$ ). The baseline TSH level was $1.31 \pm 0.67$ and $1.11 \pm 0.48 \mu \mathrm{IU} / \mathrm{mL}(p=0.565)$ in control and LT-4 groups, respectively. The baseline T4 level was $8.3 \pm 1.6 \mu \mathrm{g} / \mathrm{dL}$ in control group and $10.6 \pm 9.1$ $\mu \mathrm{g} / \mathrm{dL}$ in the LT4 group $(p=0.827)$. Tg level was significantly lower in control group than in LT-4 group (14.6 \pm 10.3 vs. $79.5 \pm 122.4 \mathrm{ng} / \mathrm{mL}, p=0.001)$. The mean nodule size of control group and LT- 4 group was 3.48 $\pm 4.36 \mathrm{~mL}$ and $4.89 \pm 4.46 \mathrm{~mL}$, respectively $(p=0.06)$. The average body weight (BW)-adjusted thyroxine dose was $1.8 \mu \mathrm{g} / \mathrm{kg} /$ day in LT-4 group. The post-treatment TSH values in LT- 4 group were maintained in the range of 0.08 to $0.35 \mu \mathrm{IU} / \mathrm{mL}$ (mean $=0.13 \pm 0.15 \mu \mathrm{IU} / \mathrm{mL}$ ). Additionally, the T4 level was increased $(10.9 \pm 2.2$ $\mu \mathrm{g} / \mathrm{dL}, p=0.023)$ and the Tg level was decreased (32.0 $\pm 51.9 \mathrm{ng} / \mathrm{mL}, p=0.006)$ significantly after thyroxine treatment (Table 1).

\section{Nodule size}

Fig. 2 shows a trend of reduction of thyroid nodule volume in control group after initial 2-year follow-up but no further volume decreases were shown after 5 years. A similar condition was observed in LT- 4 group but the reduced volume was more obvious in the initial 2 years $(\Delta$ volume change $=-0.39 \pm 2.95 \mathrm{~mL}$ in control group $v s$. $-0.90 \pm 3.98 \mathrm{~mL}$ in LT-4 group, $p=0.304)$. Changes in nodule volume were not significantly different at 2 -year and 5-year follow-up between the two groups (Fig. 2).

In LT-4 group, a gradual volume reduction was observed as early as 1 year $(3.98 \pm 3.38 \mathrm{~mL}, p=0.174)$ and was more statistically significant in 2 years $(4.10$ $\pm 4.57 \mathrm{~mL}, p=0.033$ ) when compared with baseline values $(4.89 \pm 4.46 \mathrm{~mL})$ (Table 2). However, the nodule volume increased insignificantly later during 7-year follow-up $(4.91 \pm 5.40 \mathrm{~mL}, p=0.711)$ and 9-year 


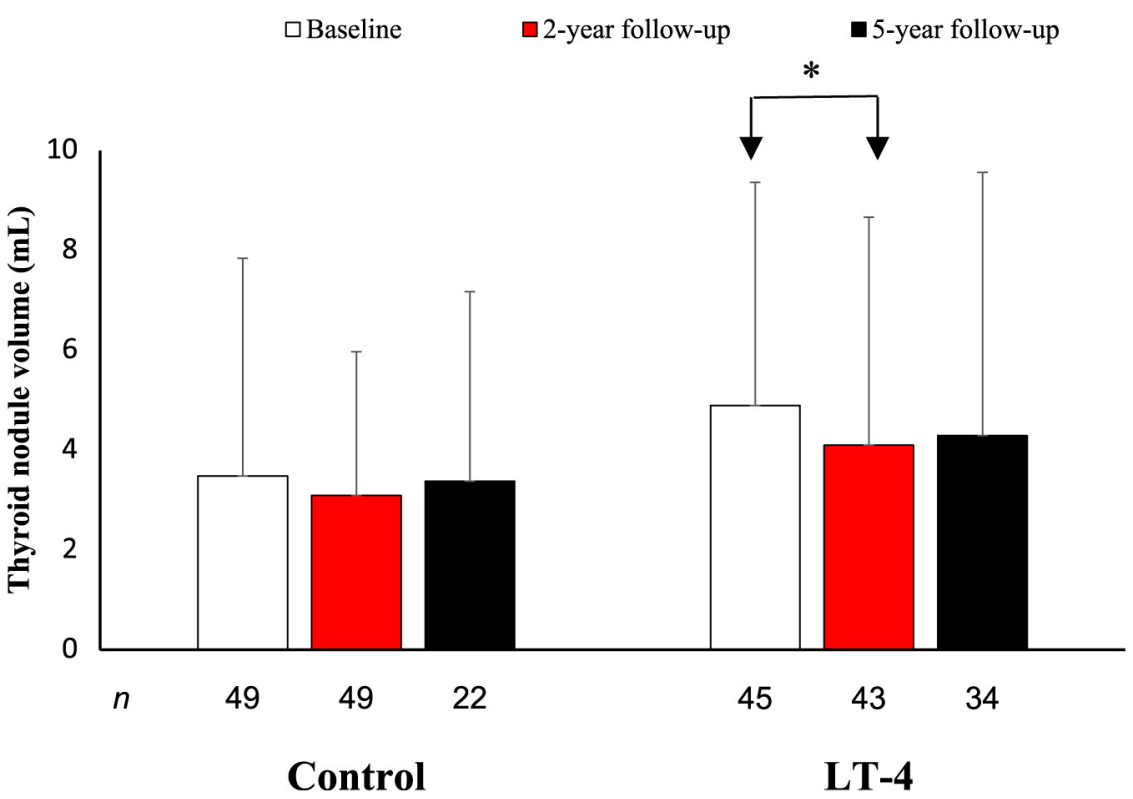

Fig. 2 Thyroid nodule volumes at baseline (White columns), during 2-year (Red columns) and 5-year follow-up (Black columns) in control and L-T4 group.

Each column indicates mean values; bars represent standard deviations. $N$ equals numbers of participants.

Nonparametric Mann-Whitney $U$ test was used for continuous variables between the two groups and Wilcoxon signed rank test was used for related continuous variables in different time interval.

* Significant difference, defined by $p$ value $<0.05$.

Table 2 Thyroid nodule volumes at baseline and during followup in LT-4 group

\begin{tabular}{llllcl}
\hline & $n$ & Range & mean \pm SD & median & $p$ value \\
\hline Baseline & 45 & $(0.18-17.76)$ & $4.89 \pm 4.46$ & 3.14 & \\
1 year & 32 & $(0.23-13.31)$ & $3.98 \pm 3.38$ & 2.96 & 0.172 \\
2 years & 43 & $(0.23-27.41)$ & $4.10 \pm 4.57$ & 2.82 & $0.033^{*}$ \\
\hline 3.5 years & 26 & $(0.04-19.09)$ & $4.57 \pm 5.13$ & 2.24 & 0.200 \\
\hline 5 years & 34 & $(0.17-27.04)$ & $4.29 \pm 5.27$ & 2.61 & 0.197 \\
\hline years & 18 & $(0.23-19.75)$ & $4.91 \pm 5.40$ & 3.74 & 0.711 \\
\hline 9 years & 8 & $(0.31-21.43)$ & $6.06 \pm 7.03$ & 3.63 & 0.208 \\
\hline
\end{tabular}

Continuous variables are presented as mean and standard deviation $($ mean $\pm \mathrm{SD})$. Nonparametric Wilcoxon Signed Rank test was used for repeated measurement.

* Significant difference, defined by $p$ value $<0.05$.

follow-up (6.06 $\pm 7.03 \mathrm{~mL}, p=0.208)$. In LT-4 group, the best value for predicting the reduction of nodule volume was observed in 21 patients $(84.0 \%)$ during 2 year follow-up when the initial nodule volume was greater than $2.6 \mathrm{~mL}(\mathrm{AUC}=0.740$, sensitivity: 0.750 , specificity: $0.733,95 \%$ CI $(0.580-0.901), p=0.010)$ (Fig. 3).

\section{Bone mineral density}

The initial BMD was evaluated by DXA in patients of LT-4 group at the age of $66.9 \pm 9.0$ years after an average thyroxine treatment duration of $61.9 \pm 9.6$ months. During the 2-year follow-up interval of BMD measurements, TSH levels in these patients were suppressed and maintained around $0.11 \pm 0.1 \mu \mathrm{IU} / \mathrm{mL}$. Changes in BMD during the 2-year follow-up showed no remarkable differences in lumbar spine (from $0.989 \pm 0.134$ to 0.981 $\pm 0.135 \mathrm{~g} / \mathrm{cm}^{2}, p=0.460$ ), total hip (from $0.806 \pm 0.091$ to $0.810 \pm 0.094 \mathrm{~g} / \mathrm{cm}^{2}, p=0.474$ ) and femoral neck (from $0.742 \pm 0.090$ to $0.750 \pm 0.083 \mathrm{~g} / \mathrm{cm}^{2}, p=0.204$ ) (Table 3).

\section{Discussion}

The natural course of thyroid goiter is not fully understood. In a series of observational studies, thyroid nodules were estimated to have grown from $15 \%$ to $69 \%$ during 5 years $[28,29]$. Such a wide range of variation was attributed to different definitions of volume increments and small sample size in those studies. For example, while an annual growth of $4.5 \%$ was reported in a cross-sectional study [30], only $15.4 \%$ of growth in nod- 


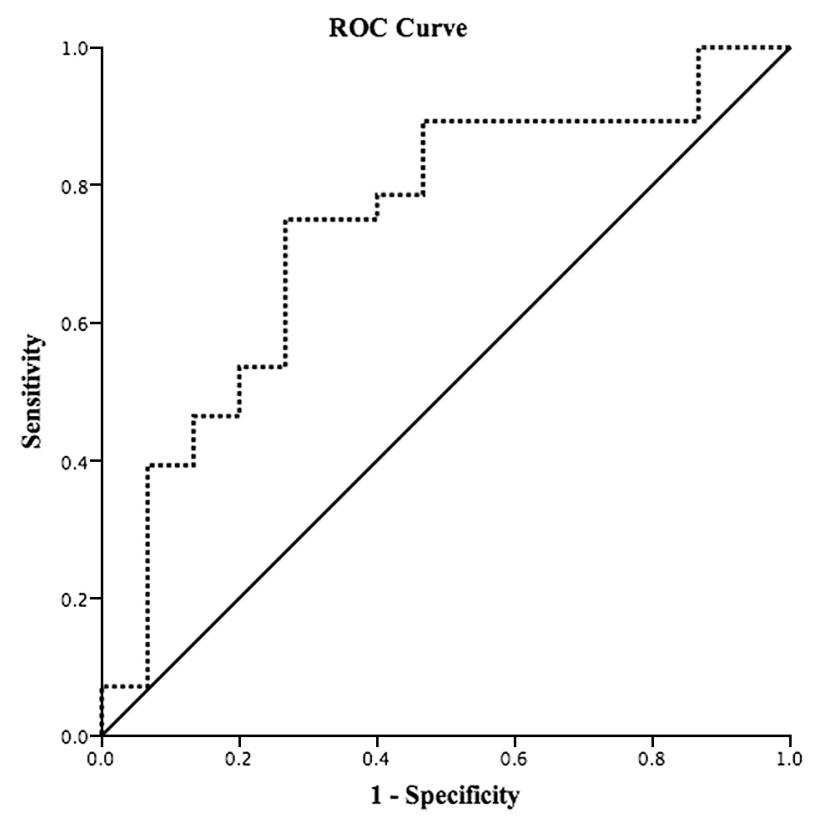

Fig. 3 ROC curve analysis was performed by SPSS to determine the best discrimination point of initial nodule volume and reduction of volume after 2-years' thyroxine treatment.

The best discrimination points of initial thyroid nodule volume determined by Youden index was located at 2.6 $\mathrm{mL}$ with a sensitivity of 0.750 and a specificity of 0.733 . Area under ROC curve was $0.740 ; p$ value $=0.010,95 \%$ CI (0.580-0.901).

Abbreviation: $\mathrm{ROC}=$ receiver operating characteristic.

Table 3 BMD changes in LT-4 group

\begin{tabular}{clll}
\hline & $\begin{array}{l}\text { Baseline } \\
(n=32)\end{array}$ & $\begin{array}{l}\text { 2-yr follow-up } \\
(n=32)\end{array}$ & $p$ value \\
\hline BMD $\left(\mathrm{g} / \mathrm{cm}^{2}\right)$ & & & \\
\hline Lumbar spine & $0.989 \pm 0.134$ & $0.981 \pm 0.135$ & 0.460 \\
Total hip & $0.806 \pm 0.091$ & $0.810 \pm 0.094$ & 0.474 \\
Femoral neck & $0.742 \pm 0.090$ & $0.750 \pm 0.083$ & 0.204 \\
T-score & & & \\
\hline Lumbar spine & $-1.595 \pm 1.121$ & $-1.662 \pm 1.124$ & 0.460 \\
Total hip & $-1.620 \pm 0.758$ & $-1.581 \pm 0.785$ & 0.475 \\
Femoral neck & $-1.985 \pm 0.749$ & $-1.937 \pm 0.696$ & 0.315 \\
\hline
\end{tabular}

Continuous variables are presented as mean and standard deviation (mean $\pm \mathrm{SD}$ ).

$p$ values were determined using the paired $t$ test.

* Significant difference, defined by $p$ value $<0.05$.

Abbreviation: BMD, bone mineral density.

ular size $>0.2 \mathrm{~mL}$ was found in patients who were younger than 60 years old in a 5 year prospective, multi- center, observation study [31]. As reported in other studies $[8,32]$, Taiwan was at one time an endemic area for goiter but, since 1958, the prevalence of goiter was remarkably reduced after iodine supplementation [33], which may correlate with the slow growing nodules found in postmenopausal women without thyroxine treatment in the present study.

The efficacy of thyroxine suppression on thyroid nodules has been controversial and is still under debate. Patients in the current study were treated by different clinicians, with various strategies for managing thyroid nodules. Treatment decisions were made after discussion with the patients. This is may be the reason why the nodule volume in control group was smaller, as patients with smaller nodules are more willing to undergo observation rather than initial medical treatment. Although Gharib et al. [7] claimed a reduction of $10 \%-20 \%$ nodule volume after 3 to 21 months thyroxine treatment, a meta-analysis by Castro and colleagues [34] reported a statistically insignificant reduction of nodule volume of more than $50 \%$ after suppressive thyroid hormone therapy for more than 6 months. Results of the present study were also contradictory since a volume reduction in the treatment group in a 2-year follow-up period was still statistically insignificant compared to results for control group.

Regarding the length of thyroxine treatment, other investigators reported a $>50 \%$ nodule volume reduction using short-term thyroxine treatment of 18 months in one study vs. 12 months in another $[9,35]$. During mean follow-up of 4 to 4.9 years, the efficacy of thyroxine treatment was not sustained in study subjects with both suppressive and non-suppressive clinical conditions $[8$, $28,36]$. Results of the present study are in agreement with those findings since a gradual nodule volume reduction nadir was found at the initial 2-year follow-up in both the treatment and control groups. However, at the end of 7-year and 9-year follow-up, the nodule size was even larger than that of the initial nodules. Thus, a duration of more than 2 years of thyroxine suppressive treatment appears to have no benefit in controlling nodule size.

Costante et al. [8] found that nodules with a smaller size $(<1.5 \mathrm{~mL})$ had a better response rate after one year of thyroxine suppressive treatment in postmenopausal women. Similarly, La Rosa et al. [2] also reported a higher frequency of positive response to thyroxine in patients with nodule volume $<5 \mathrm{~mL}$. In contrast, the present study found better responsiveness to thyroxine treatment in patients with larger thyroid nodules $(>2.6$ 
$\mathrm{mL}$ ). Some discrepancies between the Costante study and results of the present study may help to explain the differences in response rates. The Costante study, for example, included younger (aged 45-54) postmenopausal women, iodine status (mild to moderate iodine deficiency in contrast to iodine sufficient), and the exclusion of larger nodule volumes $(>12 \mathrm{~mL})$. In contrast, patients in the present study were relatively older (mean age $60.6 \pm 8.4$ years $)$ with larger nodules $(11.1 \%$ of patients had initial nodule volume larger than $12 \mathrm{~mL}$ ). Also, the typical iodine status in Taiwan is mild deficiency in women older than 45 years [37].

Since 1995, with the arrival of the ageing era, more than 20 million women were estimated to have osteoporosis worldwide [38]. The risk of fracture and associated mortality and mobility is high $(40 \%-50 \%)$ in people aged 50 and older with osteoporosis [39]. Since thyrotoxicosis, lack of estrogen and female gender are risk factors associated with osteoporosis [40, 41], the possibility of aggravating bone loss is a major concern. In the present study, minimal changes in BMD were observed in postmenopausal women under thyroxine treatment for two years even though other investigators have reported cortical bone loss in short and long term follow-up [18, 19, 42]. These inconsistencies in short-term thyroxine treatment might be due to the age-range of the participants since BMD loss is accelerated in the late perimenopausal and first postmenopausal years [43, 44]. Even with the neutral findings in the present study, serial BMD evaluations may be needed in postmenopausal women under long-term suppressive thyroxine treatment to avoid possible unwanted outcomes.

Another important issue is the influence of thyroid hormone on the cardiovascular system. Prior studies have shown that when the TSH level was $<0.10 \mathrm{mIU} / \mathrm{L}$ (subclinical hyperthyroidism) the risk of heart failure and Af are increased [45, 46]. However, other study has reported an unclear association of cardiovascular risk in patients with subclinical hyperthyroidism when TSH levels are between 0.10 and $0.44 \mathrm{mIU} / \mathrm{L}$ [47]. The average TSH level of our participants during suppressive treatment was $0.13 \pm 0.15 \mu \mathrm{IU} / \mathrm{mL}$. Furthermore, no patient experienced congestive heart failure or Af during follow- up. Nevertheless, caution is needed in the management of benign thyroid nodules, and for longer-term thyroxine treatment, the risk of congestive heart failure and Af should be taken into account.

The present study has several limitations. First, the study is retrospective, which precludes inferences of causality, and only a small number of participants were enrolled from a single medical center with unavoidable missing data. Second, it is possible that observation rather than treatment is the shared decision made by both physicians and patients with smaller thyroid nodules, which may explain why the initial nodule size was smaller in control group. Third, the baseline data of BMD and biomarkers of bone turnover were not collected from patients before thyroxine treatment. Additionally, long-term effects of thyroxine treatment on BMD were not studied.

\section{Conclusions}

In conclusion, the present study demonstrates that thyroxine suppression therapy successfully reduces the volume of thyroid nodules in postmenopausal women in the initial two years of treatment, especially in nodules with larger volume $(>2.6 \mathrm{~mL})$. Prolonged treatment for longer than two years does not improve the nodular size in this patient population. No significant BMD loss is observed during the initial two-year period.

\section{Acknowledgments}

This research was supported by Chang Gung Memorial Hospital (CORPG3F0811). This study is based in part on data from the Chang Gung Research Database provided by the Chang Gung Memorial Hospital.

\section{Disclosure}

None of the authors have any potential conflicts of interest associated with this research. No specific grants from any funding agency in the public, commercial or not-for-profit sector were received to support this study.

\section{References}

1. Morganti S, Ceda G, Saccani M, Milli B, Ugolotti D, et al. (2005) Thyroid disease in the elderly: sex-related differen- ces in clinical expression. J Endocrinol Invest 28: 101104. 
2. La Rosa GL, Lupo L, Giuffrida D, Gullo D, Vigneri R, et al. (1995) Levothyroxine and potassium iodide are both effective in treating benign solitary solid cold nodules of the thyroid. Ann Intern Med 122: 1-8.

3. Lima N, Knobel M, Cavaliere H, Sztejnsznajd C, Tomimori E, et al. (1997) Levothyroxine suppressive therapy is partially effective in treating patients with benign, solid thyroid nodules and multinodular goiters. Thyroid 7: 691-697.

4. Zelmanovitz Fv, Genro S, Gross JL (1998) Suppressive therapy with levothyroxine for solitary thyroid nodules: a double-blind controlled clinical study and cumulative meta-analyses. J Clin Endocrinol Metab 83: 3881-3885.

5. Gharib H, James EM, Charboneau JW, Naessens JM, Offord KP, et al. (1987) Suppressive therapy with levothyroxine for solitary thyroid nodules. $N$ Engl J Med 317: 70-75.

6. Mainini E, Martinelli I, Morandi G, Villa S, Stefani I, et al. (1995) Levothyroxine suppressive therapy for solitary thyroid nodule. J Endocrinol Invest 18: 796-799.

7. Gharib H, Mazzaferri EL (1998) Thyroxine suppressive therapy in patients with nodular thyroid disease. Ann Intern Med 128: 386-394.

8. Costante G, Crocetti U, Schifino E, Ludovico O, Capula C, et al. (2004) Slow growth of benign thyroid nodules after menopause: no need for long-term thyroxine suppressive therapy in post-menopausal women. $J$ Endocrinol Invest 27: 31-36.

9. Cesareo R, Iozzino M, Isgrò MA, Annunziata F, Di Stasio E (2010) Short term effects of levothyroxine treatment in thyroid multinodular disease. Endocr J 57: 803-809.

10. Sawin CT, Geller A, Wolf PA, Belanger AJ, Baker E, et al. (1994) Low serum thyrotropin concentrations as a risk factor for atrial fibrillation in older persons. $N$ Engl J Med 331: 1249-1252.

11. Uzzan B, Campos J, Cucherat M, Nony P, Boissel JP, et al. (1996) Effects on bone mass of long term treatment with thyroid hormones: a meta-analysis. J Clin Endocrinol Metab 81: 4278-4289.

12. Gencer B, Collet TH, Virgini V, Auer R, Rodondi N (2013) Subclinical thyroid dysfunction and cardiovascular outcomes among prospective cohort studies. Endocr Metab Immune Disord Drug Targets 13: 4-12.

13. Blum MR, Bauer DC, Collet TH, Fink HA, Cappola AR, et al. (2015) Subclinical thyroid dysfunction and fracture risk: a meta-analysis. JAMA 313: 2055-2065.

14. Lee SJ, Kim KM, Lee EY, Song MK, Kang DR, et al. (2016) Low normal TSH levels are associated with impaired BMD and hip geometry in the elderly. Aging Dis 7: 734-743.

15. Bassett JD, Williams GR (2003) The molecular actions of thyroid hormone in bone. Trends Endocrinol Metab 14: 356-364.
16. Gogakos AI, Bassett JD, Williams GR (2010) Thyroid and bone. Arch Biochem Biophys 503: 129-136.

17. Surks MI, Ortiz E, Daniels GH, Sawin CT, Col NF, et al. (2004) Subclinical thyroid disease: scientific review and guidelines for diagnosis and management. JAMA 291: 228-238.

18. Müller CG, Bayley TA, Harrison JE, Tsang R (1995) Possible limited bone loss with suppressive thyroxine therapy is unlikely to have clinical relevance. Thyroid 5: 81-87.

19. Appetecchia M (2005) Effects on bone mineral density by treatment of benign nodular goiter with mildly suppressive doses of L-thyroxine in a cohort women study. Horm Res 64: 293-298.

20. Riggs BL, Melton LJ 3rd (1995) The worldwide problem of osteoporosis: insights afforded by epidemiology. Bone 17: S505-S511.

21. Chow S, Huang C, Lee Y (1997) Demographic characteristics and medical aspects of menopausal women in Taiwan. J Formos Med Assoc 96: 806-811.

22. Chen SC, Lo TC, Chang JH, Kuo HW (2014) Variations in aging, gender, menopause, and obesity and their effects on hypertension in Taiwan. Int J Hypertens 2014: 515297.

23. Cibas ES, Ali SZ (2009) The Bethesda system for reporting thyroid cytopathology. Am J Clin Pathol 132: 658665.

24. Andrioli M, Carzaniga C, Persani L (2013) Standardized ultrasound report for thyroid nodules: the endocrinologist's viewpoint. Eur Thyroid J 2: 37-48.

25. Gallo M, Pesenti M, Valcavi R (2003) Ultrasound thyroid nodule measurements: the "gold standard" and its limitations in clinical decision making. Endocr Pract 9: 194199.

26. Kanis J, Glüer CC (2000) An update on the diagnosis and assessment of osteoporosis with densitometry. Osteoporos Int 11: 192-202.

27. Youden WJ (1950) Index for rating diagnostic tests. Cancer 3: 32-35.

28. Quadbeck B, Pruellage J, Roggenbuck U, Hirche H, Janssen OE, et al. (2002) Long-term follow-up of thyroid nodule growth. Exp Clin Endocrinol Diabetes 110: 348354.

29. Alexander EK, Hurwitz S, Heering JP, Benson CB, Frates $\mathrm{MC}$, et al. (2003) Natural history of benign solid and cystic thyroid nodules. Ann Intern Med 138: 315-318.

30. Berghout A, Wiersinga WM, Smits NJ, Touber JL (1990) Interrelationships between age, thyroid volume, thyroid nodularity, and thyroid function in patients with sporadic nontoxic goiter. Am J Med 89: 602-608.

31. Durante C, Costante G, Lucisano G, Bruno R, Meringolo $\mathrm{D}$, et al. (2015) The natural history of benign thyroid nodules. JAMA 313: 926-935.

32. Kuma K, Matsuzuka F, Yokozawa T, Miyauchi A, Sugawara M (1994) Fate of untreated benign thyroid nod- 
ules: results of long-term follow-up. World J Surg 18: 495-498.

33. Chen K, Lin CC, Wu HY, Sun C, Chen C, et al. (1964) Pilot project on endemic goiter prevention with iodized salt in Hsinchu County, Taiwan, China. Memoirs Coll Med Nat Taiwan Univ 10: 73-92 (In Chinese).

34. Castro MR, Caraballo PJ, Morris JC (2002) Effectiveness of thyroid hormone suppressive therapy in benign solitary thyroid nodules: a meta-analysis. J Clin Endocrinol Metab 87: 4154-4159.

35. Wemeau JL, Caron P, Schvartz C, Schlienger JL, Orgiazzi J, et al. (2002) Effects of thyroid-stimulating hormone suppression with levothyroxine in reducing the volume of solitary thyroid nodules and improving extranodular nonpalpable changes: a randomized, double-blind, placebocontrolled trial by the French Thyroid Research Group. $J$ Clin Endocrinol Metab 87: 4928-4934.

36. Puzziello A, Carrano M, Angrisani E, Marotta V, Faggiano A, et al. (2014) Evolution of benign thyroid nodules under levothyroxine non-suppressive therapy. $J$ Endocrinol Invest 37: 1181-1186.

37. Tang KT, Wang FF, Pan WH, Lin JD, Won GS, et al. (2016) Iodine status of adults in Taiwan 2005-2008, 5 years after the cessation of mandatory salt iodization. $J$ Formos Med Assoc 115: 645-651.

38. Melton LJ 3rd (1995) Perspectives: how many women have osteoporosis now? J Bone Miner Res 10: 175-177.

39. Johnell O, Kanis J (2005) Epidemiology of osteoporotic fractures. Osteoporos Int 16 Suppl 2: S3-S7.

40. Fraser SA, Smith DA, Anderson JB, Wilson GM (1971) Osteoporosis and fractures following thyrotoxicosis.
Lancet 297: 981-983.

41. Riggs BL, Khosla S, Melton LJ 3rd (1998) A unitary model for involutional osteoporosis: estrogen deficiency causes both type I and type II osteoporosis in postmenopausal women and contributes to bone loss in aging men. J Bone Miner Res 13: 763-773.

42. Guo CY, Weetman AP, Eastell R (1997) Longitudinal changes of bone mineral density and bone turnover in postmenopausal women on thyroxine. Clin Endocrinol (Oxf) 46: 301-307.

43. Finkelstein JS, Brockwell SE, Mehta V, Greendale GA, Sowers MR, et al. (2008) Bone mineral density changes during the menopause transition in a multiethnic cohort of women. J Clin Endocrinol Metab 93: 861-868.

44. De Rosa G, Testa A, Giacomini D, Carrozza C, Astazi P, et al. (1997) Prospective study of bone loss in pre- and post-menopausal women on L-thyroxine therapy for nontoxic goitre. Clin Endocrinol (Oxf) 47: 529-535.

45. Gencer B, Collet T-H, Virgini V, Bauer DC, Gussekloo J, et al. (2012) Subclinical thyroid dysfunction and the risk of heart failure events: an individual participant data analysis from six prospective cohorts. Circulation 126: 10401049.

46. Collet T-H, Gussekloo J, Bauer DC, den Elzen WP, Cappola AR, et al. (2012) Subclinical hyperthyroidism and the risk of coronary heart disease and mortality. Arch Intern Med 172: 799-809.

47. Donangelo I, Suh SY (2017) Subclinical hyperthyroidism: when to consider treatment. Am Fam Physician 95: 710716. 